\title{
Monocyte Adhesion to Activated Aortic Endothelium: Role of L-Selectin and Heparan Sulfate Proteoglycans
}

\author{
Laura Giuffrè,* Anne-Sophie Cordey,* Natacha Monai,* Yanik Tardy, ${ }^{\star}$ Marc Schapira,* \\ and Olivier Spertini* \\ *Division of Hematology, the Hematology Central Laboratory of the University of Lausanne, 1011-CHUV Lausanne; and \\ *Biomedical Engineering Laboratory of the Swiss Federal Institute of Technology, 1015-PSE-Ecublens, Switzerland
}

\begin{abstract}
This study examines the role of L-selectin in monocyte adhesion to arterial endothelium, a key pathogenic event of atherosclerosis. Using a nonstatic (rotation) adhesion assay, we observed that monocyte binding to bovine aortic endothelium at $4^{\circ} \mathrm{C}$ increased four to nine times upon endothelium activation with tumor necrosis factor (TNF)- $\alpha$. mAb-blocking experiments demonstrated that L-selectin mediates a major part (64 $\pm 18 \%)$ of monocyte attachment. Videomicroscopy experiments performed under flow indicated that monocytes abruptly halted on 8 -h TNF- $\alpha-$ activated aortic endothelium, $\sim 80 \%$ of monocyte attachment being mediated by L-selectin. Flow cytometric studies with a L-selectin/IgM heavy chain chimeric protein showed calcium-dependent L-selectin binding to cytokine-activated and, unexpectedly, unactivated aortic cells. Soluble L-selectin binding was completely inhibited by anti-L-selectin $\mathrm{mAb}$ or by aortic
\end{abstract}

cell exposure to trypsin. Experiments with cycloheximide, chlorate, or neuraminidase showed that protein synthesis and sulfate groups, but not sialic acid residues, were essential for L-selectin counterreceptor function. Moreover, heparin lyases partially inhibited soluble L-selectin binding to cytokine-activated aortic cells, whereas a stronger inhibition was seen with unstimulated endothelial cells, suggesting that cytokine activation could induce the expression of additional ligand(s) for L-selectin, distinct from heparan sulfate proteoglycans. Under flow, endothelial cell treatment with heparinase inhibited by $\sim 80 \%$ monocyte attachment to TNF- $\alpha$-activated aortic endothelium, indicating a major role for heparan sulfate proteoglycans in monocyte-endothelial interactions. Thus, L-selectin mediates monocyte attachment to activated aortic endothelium, and heparan sulfate proteoglycans serve as arterial ligands for monocyte L-selectin.
L TIN plays a major role in the regulation of the inflammatory response by mediating the initial attachment of leukocytes along endothelial cells lining postcapillary venules (4, 42, 43, 44, 85, 89-91). L-selectin shares common structural features with $\mathrm{P}$ - and E-selectin, including an $\mathrm{NH}_{2}$-terminal C-type lectin domain, an EGFlike domain, short consensus repeats, a transmembrane domain, and a short cytoplasmic tail $(38,39,83,84)$. L-selectin, which is expressed by most leukocytes (1, 16, $27,39)$, supports leukocyte tethering and rolling along vascular endothelium by interacting with carbohydrates presented by specific endothelial cell ligands (38, 41, 42, 53, $79,84,89,90)$. P-selectin is rapidly expressed by activated platelets and endothelial cells exposed to thrombin or histamine $(26,37,45,51,52)$. E-selectin is expressed by endothelial cells upon activation by interleukin-1, tumor necrosis factor $(\mathrm{TNF})^{1}-\alpha$, or endotoxin $(12,13,46,47)$.

$\overline{\text { Please ad}} d$ ress all correspondence to Dr. Olivier Spertini, Division of Hematology, University of Lausanne, 1011-CHUV Lausanne, Switzerland.

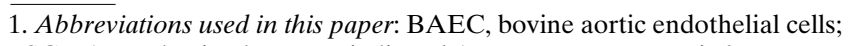
PSGL-1, P-selectin glycoprotein ligand-1; TNF, tumor necrosis factor.
Selectins bind to various carbohydrate ligands $(2,5,38$, $53,65,79,84,88)$, most of them containing a lactosamine backbone and carrying sialylated, sulfated, and/or fucosylated sequences. Some complex carbohydrates, such as the tetrasaccharide sialyl Lewis ${ }^{\mathrm{x}}$, are ligands for all three selectins; other carbohydrates interact only with one or two of them $(23,88)$. Selectins have also been shown to bind to complex sulfated carbohydrates that do not contain sialic acid or fucose residues, for example, heparin, sulfatide, or the HNK-1-reactive sulfoglucuronyl glycolipids $(5,55,56$, 88). Monovalent carbohydrates have low affinity for selectins, and their role in supporting leukocyte rolling is unclear $(17,33,53)$. However, when oligosaccharides are presented by a protein backbone, high affinity multivalent interactions can be observed $(19,53,65,88)$. Several glycoproteins have high affinity for selectins. Most of them are sialylated or sulfated mucin-like glycoproteins with many serine and threonine residues that are potential sites for attachment of O-linked glycans. Four mucinlike ligands for L-selectin have been identified on high endothelial venules of mouse lymph nodes: GlyCAM-1, MadCAM-1, CD34, and gp 200, a glycoprotein that has not yet been 
cloned $(9,11,30,40)$. GlyCAM-1 is secreted and might serve to modulate L-selectin-mediated attachment of lymphocytes to peripheral lymph node high endothelial venules $(15,40)$. MadCAM-1 is present on mesenteric lymph nodes as a multifunctional ligand recognized by both $\alpha 4 \beta 7$ integrin and L-selectin (11). CD34 is the major ligand for L-selectin in peripheral and mesenteric lymph node high endothelial venules as well as in human tonsil $(9,64)$. It is also expressed in larger vessels (10) and on hematopoietic cell progenitors (36). However, CD34 function in large blood vessels has not been explored. Sialic acid, fucose, and sulfate residues are required for the function of GlyCAM-1 and CD34 $(30,32)$. These residues as well as three $\mathrm{NH}_{2}$-terminal tyrosine sulfates have also been reported to be essential for the interaction of P-selectin glycoprotein ligand-1 (PSGL-1) with P-selectin or L-selectin $(63,68,78,93)$.

Although in vitro and in vivo studies support the existence of carbohydrate ligands for L-selectin on activated nonlymphoid vascular endothelium, the identity of these ligands has not been established $(34,35,42,43,44,48,71$, $73,76,77,85,89,90,92)$. Staining of calf pulmonary artery endothelial cell line or human umbilical vein endothelial cells with an L-selectin/IgG1 heavy chain chimera has revealed the presence of an intracellular pool of heparin-like ligands for the chimeric protein (57). Additional studies have indicated that L-selectin interacts with heparan sulfate proteoglycans associated with or secreted by cultured endothelial cells (58). However, the capacity of these proteoglycans to support leukocyte attachment to the vascular endothelium has not been examined.

Monocyte attachment to arterial endothelium is considered to be a key event of the early phase of atherosclerosis. However, little information is available on the molecular mechanisms that mediate monocyte-endothelial interactions. Earlier reports have shown that L-selectin is the major receptor for monocyte attachment to activated venous endothelium in nonstatic adhesion assay (76) and under flow conditions $(48,49)$. The study described here was designed to investigate the role of L-selectin and aortic ligands in mediating monocyte attachment to resting and activated arterial endothelium.

\section{Materials and Methods}

\section{Endothelial Cell Culture}

Bovine aortic endothelial cells (BAEC; provided by J.-A. Haeffliger, Department of Internal Medicine, University Hospital, Lausanne), isolated by collagenase treatment of bovine aorta, were established as primary culture and serially passaged in RPMI 1640 medium (Gibco Laboratories, Paisley, Scotland) supplemented with 10\% FCS (Gibco Laboratories). For adhesion studies, BAEC (passages 3-5) were plated on $60 \times 15-\mathrm{mm}$ tissue culture dishes (Becton Dickinson, Basel, Switzerland) and grown within a 2-cm-diam circle delineated by a ring of $12 \mathrm{M}$ polysiloxane as described elsewhere $(72,73)$. For use in the parallel flow chamber, BAEC were plated on 25-mm circular glass coverslips (Bellco Glass, Inc., Vineland, $\mathrm{NJ})$. Because a lower reactivity of BAEC with L-selectin $/ \mu$ chimera was observed with endothelial passages $>8$, only passages $3-5$ were used to perform immunofluorescence analysis or adhesion assays.

\section{Monocyte Isolation}

Human monocytes were prepared from blood buffy coats obtained from healthy blood donors. Monocytes were isolated by centrifugation on Ficoll-Hypaque (Pharmacia, Uppsala, Sweden) and adhesion on gelatine
$1 \%$ (Sigma Chemical Co., St. Louis, MO) at $37^{\circ} \mathrm{C}$. Nonadherent cells were removed by three washes with HBSS (Gibco Laboratories). Adherent cells were then detached with PBS containing $5 \mathrm{mM}$ EDTA and washed again in RPMI 1640 (Gibco Laboratories). The cell suspension obtained by this method contained $>95 \%$ monocytes as determined by Giemsa stain and immunostaining with phycoerythrin-conjugated anti-CD14 mAb Leu-M3 (Becton Dickinson). L-selectin and CD14 expression by whole blood and isolated monocytes was evaluated by double immunofluorescence and flow cytometry (see below). Monocyte isolation caused a 40 $50 \%$ loss of L-selectin expression. Isolated monocytes were kept on ice and used immediately after isolation.

\section{$m A b s$}

Anti-L-selectin mAbs anti-LAM1-3, -4, and -11 and anti-VCAM-1 mAb HAE2 (all IgG1) were produced as described $(72,73)$. mAbs were purified from hybridoma culture supernatants on Affigel protein A (Bio-Rad, Glattbrugg, Switzerland). For cell adhesion-blocking experiments, purified $\mathrm{mAb}$ IgG was used at $10 \mu \mathrm{g} / \mathrm{ml}$. For chimeric protein-binding inhibition experiments, purified $\mathrm{mAb} \operatorname{IgG}$ was used at $50 \mu \mathrm{g} / \mathrm{ml}$.

\section{Monocyte-Endothelial Interactions under Rotation}

Cell attachment assays were carried out under rotation as previously described $(73,76,77)$. BAEC, grown to confluence on tissue culture dishes, were stimulated for $8 \mathrm{~h}$ with $100 \mathrm{U} / \mathrm{ml}$ TNF- $\alpha$ (Boehringer Mannheim, Mannheim, Germany). After washing, cytokine-activated endothelial cells were preincubated for 15 min with medium alone (RPMI 1640/5\% FCS) or with medium supplemented with anti-VCAM-1 mAb, L-selectin/ $\mu$, or $\mathrm{CD} 4 / \mu$ chimeric proteins. Monocytes $\left(4 \times 10^{6}\right.$ cells $)$ were preincubated for $15 \mathrm{~min}$ on ice in $120 \mu \mathrm{l}$ of medium (RPMI $1640 / 5 \%$ FCS) or in medium supplemented with $\mathrm{mAb}$. Endothelial cell monolayers were washed before adding monocytes. After $30 \mathrm{~min}$ of incubation at $4^{\circ} \mathrm{C}$ under rotation at $72 \mathrm{rpm}$, nonadherent cells were discarded. Petri dishes were then placed vertically in $2 \%$ glutaraldhehyde and fixed overnight. The number of adherent monocytes was counted in six to eight microscopic fields $\left(0.5 \mathrm{~mm}^{2}\right.$ per field), and the results were expressed as mean \pm 1 SD.

\section{Monocyte-Endothelial Interactions under Flow}

Well-defined laminar flow was produced over confluent endothelial cell monolayers on $25-\mathrm{mm}$ circular glass coverslips introduced in a parallel plate flow chamber (70). Monocytes were suspended at $0.5 \times 10^{6} / \mathrm{ml}$ in RPMI 1640 medium and perfused at room temperature $\left(18^{\circ} \mathrm{C}\right)$ through the chamber at a shear stress of 1.8 dynes $/ \mathrm{cm}^{2}$ via a syringe pump (model 22; Harvard Apparatus, Indulab AG, Switzerland). Monocyte-endothelial interactions were visualized using a phase-contrast videomicroscope (Axiovert; Carl Zeiss, Lausanne, Switzerland) and CCD videocamera (model XC73CE; Sony, Japan) and videotaped (Panasonic s-VHS recorder; TSA Telecom, Lausanne, Switzerland). Endothelial cell monolayers were cultured for $8 \mathrm{~h}$ in medium or in medium containing $100 \mathrm{U} / \mathrm{ml} \mathrm{TNF}-\alpha$ and then treated for $20 \mathrm{~min}$ with saturating levels of chimeric proteins. To determine the involvement of endothelial glycosaminoglycans, endothelial monolayers were incubated for $45 \mathrm{~min}$ with heparinase I $(1,200 \mathrm{mU} / \mathrm{ml})$ or hyaluronidase $(200 \mathrm{mU} / \mathrm{ml})$ and then extensively washed with medium. Monocytes were pretreated for $15 \mathrm{~min}$ with saturating concentrations of anti-L-selectin $\mathrm{mAb}$ at $4^{\circ} \mathrm{C}$ and then suspended in medium. Stable adhesion was determined between 10 and 12 min of monocyte perfusion by analyzing 12-14 random fields $\left(0.14 \mathrm{~mm}^{2} /\right.$ field, $\times 20$ objective $)$. Monocytes were considered as adherent after $20 \mathrm{~s}$ of stable contact. The rate of initial attachment was assessed by counting the number of monocytes that interacted with endothelial cell monolayers during the first $5 \mathrm{~min}$ of the experiments.

\section{Production of L-Selectin/ $\mu$ Chimeric Protein}

The L-selectin/ $\mu$ chimeric protein was prepared by a method described in detail elsewhere (78). Briefly, sequences encoding the lectin domain, the EGF-like domain, and the first two short consensus repeats of L-selectin were amplified by PCR using synthetic oligonucleotides. An artificial splice donor site was introduced at the $3^{\prime}$ end of the PCR product. The PCR product was then subcloned in a plasmid containing the $\mathrm{CH} 2, \mathrm{CH} 3$, and $\mathrm{CH} 4$ domains of IgM heavy chain $(\mu)$ in genomic configuration (kindly provided by A. Traunecker, Basel Institute for Immunology, Basel, Switzerland). After digestion with NotI and XhoI, the $\mathrm{pL}$-selectin $/ \mu$ fragment was subcloned in the pcDNAI expression vector (Invitrogen, San Diego, $\mathrm{CA})$. A CD $4 / \mu$ chimera was constructed by substituting the L-selectin 
coding sequence in pcDNA I L-selectin/ $\mu$ with a CD4 fragment encoding the first two $\mathrm{NH}_{2}$-terminal domains of CD4. Chimeric molecules were produced in COS cells transiently transfected with appropriate cDNAs. Chimeras were used as concentrated COS cell conditioned media or after purification by immunoadsorption to immobilized anti-LAM1-3 mAb (77). The molecular characteristics of L-selectin/ $\mu$ chimera were analyzed by SDS-PAGE. In reducing conditions, purified L-selectin/ $\mu$ migrated with molecular masses ranging from 95,000 to 110,000 daltons. In nonreducing conditions, the decameric L-selectin/ $\mu$ chimera migrated as a single band of very high molecular mass remaining at the end of the migration in the $3.75 \%$ SDS-polyacrylamide stacking gel. No additional band of lower molecular mass was observed in the $7.5 \%$ SDS-polyacrylamide running gel. The concentration of L-selectin/ $\mu$ was measured by ELISA as previously described $(75,77)$. The concentration of CD4/ $\mu$ chimera was determined by ELISA using goat anti-human IgM heavy chain polyclonal antibody as capture antibody (Vector Laboratories, Inc., Burlingame, CA). The chimeric protein was then detected with biotinylated polyclonal goat anti-human IgM heavy chain antibody (Vector Laboratories, Inc.), avidin-HRP (Pierce, Oud-Beijerland, The Netherlands), and $O$-phenylendiamine $(0.125 \%$, wt/

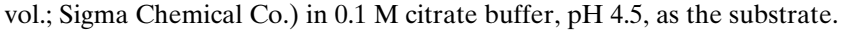
$\mathrm{E}$ - or P-selectin $/ \mu$ chimeric protein concentration was determined using purified L-selectin/ $\mu$ chimera and purified human IgM as standards. Samples were run in triplicate at 1:500 to 1:5,000 dilutions. Under these conditions, a linear relationship was observed between signal intensity and protein concentration. Absorbance at $490 \mathrm{~nm}$ was measured using an ELISA reader (model MR 5000; Dynatech Laboratories, Inc., Chantilly, VA).

\section{Immunofluorescence Analysis}

Indirect immunofluorescence analysis was performed using suspended BAEC, which had been detached from plastic flasks with PBS/5 mM EDTA. After three washes in RPMI 1640/1\% FCS medium, BAEC were incubated for $30 \mathrm{~min}$ at $4^{\circ} \mathrm{C}$ with $\mathrm{L}$-selectin $/ \mu$ or CD $4 / \mu$ chimera. Chimeric protein binding to suspended endothelial cells was revealed using FITCconjugated rabbit anti-human IgM heavy chain (Dako, Glostrup, Denmark). Flow cytometry was performed using a cytofluorimeter (EPICS Profile; Coulter Corp., Hialeah, FL). Cells were gated by forward- and side-scatter signals. 5,000 cells were analyzed in each experiment.

\section{Glycosaminoglycan Characterization}

Endothelial cells were incubated with various enzymes for $45 \mathrm{~min}$ at $37^{\circ} \mathrm{C}$ in $25 \mu \mathrm{l}$ RPMI 1640. Concentration curves were done for each enzyme. Optimal inhibition of L-selectin/ $\mu$ binding was observed at the chosen enzyme concentrations. Heparinase I (Sigma Chemical Co.) was used at 600 $\mathrm{mU}$, and heparitinase II (Seikagaku Corporation, Tokyo, Japan) was used at $4 \mathrm{mU}$. In other experiments, BAEC were incubated with chondroitinase ABC (200-800 mU; Sigma Chemical Co.) or hyaluronidase (200 mU; Sigma Chemical Co.). In experiments investigating the role of sialic acid, BAEC were incubated with Vibrio cholerae neuraminidase $(750 \mathrm{mU} / \mathrm{ml}$; Boehringer Mannheim) or Arthrobacter ureafaciens neuraminidase (200 $\mathrm{mU} / \mathrm{ml}$; Oxford Glycosystems, Ltd., Abingdon, UK). At this concentration, neuraminidase completely inhibited CSLEX-1 mAb binding to KG-1 cells treated with this neuraminidase $(100 \mathrm{U} / \mathrm{ml})$. The role of sulfate was evaluated by culturing trypsinized BAEC $(5 \mu \mathrm{g} / \mathrm{ml}$ trypsin for $30 \mathrm{~min}$ at $37^{\circ} \mathrm{C}$ ) for $24 \mathrm{~h}$ in RPMI 1640 medium $/ 10 \%$ FCS in the presence of $10 \mathrm{mM}$ sodium chlorate. In additional experiments, BAEC were cultured with cycloheximide $(10 \mu \mathrm{g} / \mathrm{ml})$ for $30 \mathrm{~min}$ before and during TNF- $\alpha$ treatment.

\section{Statistical Analysis}

Analysis of variance (ANOVA) and the Bonferroni multiple comparisons test were used to assess statistical significance between the different treatments versus control when three or more groups were analyzed; the Mann-Whitney test was used to compare the median of two unpaired groups, and the Wilcoxon signed rank test was used for paired groups. $P$ values $<0.05$ were considered significant.

\section{Results}

\section{Role of L-Selectin in Mediating Monocyte Adhesion to Cytokine-activated Aortic Endothelium}

Monocyte adhesion assays were performed at $4{ }^{\circ} \mathrm{C}$ under rotation. In these conditions, where L-selectin shedding is minimal and CD18-mediated adhesion is inactive (50, 73, $74,76)$, few monocytes attached to unactivated BAEC monolayers $(84 \pm 20$ monocytes/field, mean $\pm \mathrm{SD}, n=6)$. When BAEC were activated for $8 \mathrm{~h}$ with TNF- $\alpha$ (100 U/ $\mathrm{ml}$ ), a significant increase in monocyte adhesion was observed (four- to ninefold, $n=6$ ). Thus, in the experiment illustrated in Fig. 1, the number of monocytes attached to BAEC increased from $94 \pm 10$ to $425 \pm 33$ /field upon endothelium activation with $\mathrm{TNF}-\alpha$ (Fig. 1, medium). The mechanism responsible for this observation was investigated with mAbs against L-selectin or VCAM-1. Cell binding inhibition studies revealed that monocyte adhesion to cytokine-activated BAEC monolayers was inhibited by $64 \pm 18 \%$ (mean $\pm \mathrm{SD}, n=6, P<0.005)$ when monocytes were pretreated with the adhesion-blocking mAb anti-LAM1-3 (Fig. 1) (73, 76). Cell adhesion was not significantly inhibited in experiments with anti-LAM1-10 (not illustrated) or anti-LAM1-11 mAbs (Fig. 1), which recognize nonfunctional domains of L-selectin. A role for VCAM-1 in mediating monocyte attachment to activated BAEC was demonstrated by the capacity of the antiVCAM-1 mAb HAE-2 to inhibit monocyte adhesion by $38 \pm 6 \%$ (mean $\pm \mathrm{SD}, n=3, P<0.01$ ) (Fig. 1). However, the results with anti-LAM1-3 indicate that L-selectin plays a predominant role in monocyte attachment to cytokine-activated arterial endothelium under nonstatic conditions.

The notion that L-selectin could play a major role in the attachment of monocytes to cytokine-activated arterial endothelium was evaluated further in experiments comparing the effect of L-selectin/ $\mu$ and CD $4 / \mu$ chimera on the monocyte-binding capacity of BAEC monolayers. Whereas monocyte binding was not inhibited by pretreatment of BAEC monolayers with CD4/ $\mu(30 \mu \mathrm{g} / \mathrm{ml})$, strong inhibition (56 \pm

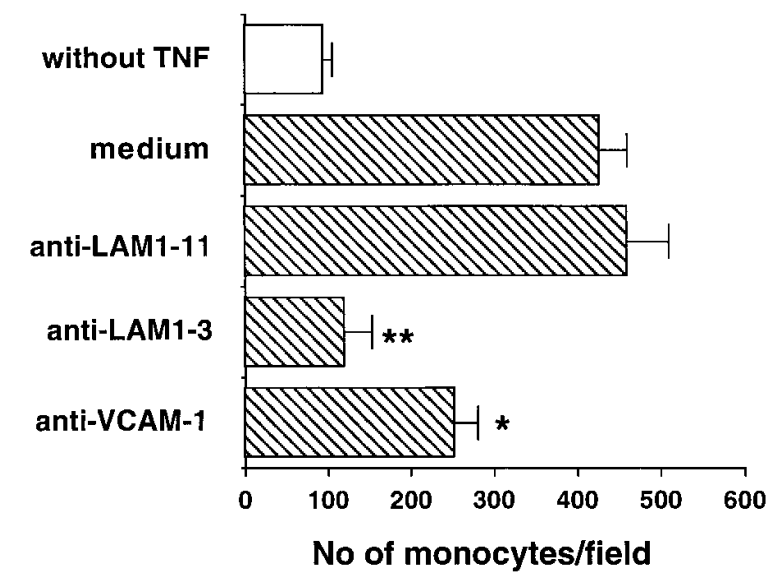

Figure 1. Monocyte attachment to unstimulated or TNF- $\alpha$-activated aortic endothelium under rotation: inhibition by mAbs. Endothelial monolayers were activated for $8 \mathrm{~h}$ with TNF- $\alpha(100$ $\mathrm{U} / \mathrm{ml})$. BAEC were preincubated with medium or anti-VCAM-1 $\mathrm{mAb}$ (HAE-2). Monocytes were preincubated with medium, blocking anti-L-selectin mAb anti-LAM1-3 or control mAb anti-LAM1-11. Adhesion assays were carried out under rotation for $30 \mathrm{~min}$ at $4^{\circ} \mathrm{C}$. Data are expressed as means $\pm \mathrm{SD}$. Results are representative of those obtained in six experiments. ${ }^{*} P<0.01$. ** Statistically significant $(P<0.005)$ difference in adhesion relative to control. 


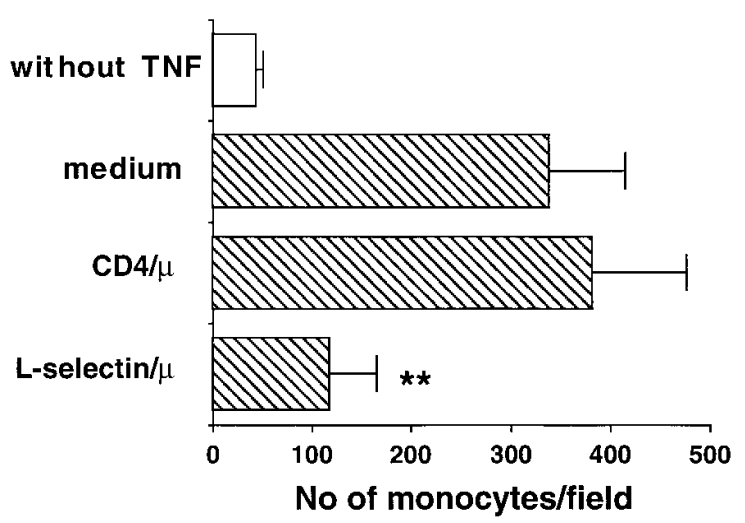

Figure 2. Monocyte attachment to unstimulated or TNF- $\alpha$-activated aortic endothelium under rotation: inhibition by chimeric proteins. Endothelial monolayers were activated for $8 \mathrm{~h}$ with TNF- $\alpha(100 \mathrm{U} / \mathrm{ml})$. Unstimulated and TNF-activated BAEC were then preincubated with medium, L-selectin $/ \mu$, or $\mathrm{CD} 4 / \mu$. Adhesion assays were carried out under rotation for $30 \mathrm{~min}$ at $4^{\circ} \mathrm{C}$. Data are expressed as means $\pm \mathrm{SD}$. Results are representative of three experiments. $* * P<0.005$.

$9 \%, n=3, P<0.005)$ was observed when monolayers were preincubated with L-selectin $/ \mu(50 \mu \mathrm{g} / \mathrm{ml})($ Fig. 2).

The role of L-selectin in mediating monocyte primary adhesion was further examined in a parallel flow chamber at a shear stress of 1.8 dynes $/ \mathrm{cm}^{2}$ (70). All monocytes interacting with endothelial monolayers during the first 5 min of the experiment were counted. Most of these cells were rolling before being abruptly halted and becoming stably adherent or detaching. The inhibition of L-selectin with the function-blocking $\mathrm{mAb}$ anti-LAM1-3 reduced monocyte primary adhesion to 8 -h $\mathrm{TNF}-\alpha$-activated endothelium by $78 \pm 12 \%$ (mean $\pm \mathrm{SD}, n=4$ ). Thus, after pretreatment with anti-LAM1-3 mAb, only $209 \pm 44$ monocytes $/ \mathrm{mm}^{2}$ (mean $\left.\pm \mathrm{SD}, n=4\right)$ interacted with activated endothelium, whereas $970 \pm 84 / \mathrm{mm}^{2}$ interacting monocytes $/ \mathrm{mm} 2$ were observed after pretreatment with the nonblocking anti-LAM1-11 mAb (not illustrated). Pretreatment of endothelial cells with L-selectin $/ \mu$ similarly reduced monocyte primary adhesion by $65 \pm 14 \%$ (mean $\pm \mathrm{SD}, n=3$ ). In contrast, no inhibition was observed when endothelium was pretreated with the control chimeric protein $\mathrm{CD} 4 / \mu$. The number of stably adherent monocytes at the end of the 12-min flow experiments was strongly reduced by pretreating monocytes with the antiLAM1-3 mAb ( $83 \pm 8 \%$; mean $\pm \mathrm{SD}, n=4)$ or endothelial cell monolayers with L-selectin/ $\mu$ chimera $(71 \pm 9 \%$; mean $\pm \mathrm{SD}, n=3)$. In the experiment illustrated in Fig. 3, $97 \pm 30$ (mean $\pm \mathrm{SD}, n=13$ ) adherent monocytes $/ \mathrm{mm}^{2}$ were observed after monocyte preincubation with antiLAM1-3, and $413 \pm 56$ monocytes $/ \mathrm{mm}^{2}$ were observed after pretreatment with anti-LAM1-11 mAb; in the same experiment, $130 \pm 31$ (mean $\pm \mathrm{SD}, n=13$ ) monocytes $/ \mathrm{mm}^{2}$ adhered to activated endothelium pretreated with L-selectin/ $\mu$, whereas $380 \pm 45$ monocytes adhered to monolayers pretreated with $\mathrm{CD} 4 / \mu(50 \mu \mathrm{g} / \mathrm{ml})$.

\section{Monocyte Adhesion to Cytokine-activated Aortic Endothelial Cells: Kinetic Analysis}

Monocyte adhesion to BAEC was determined under rota-

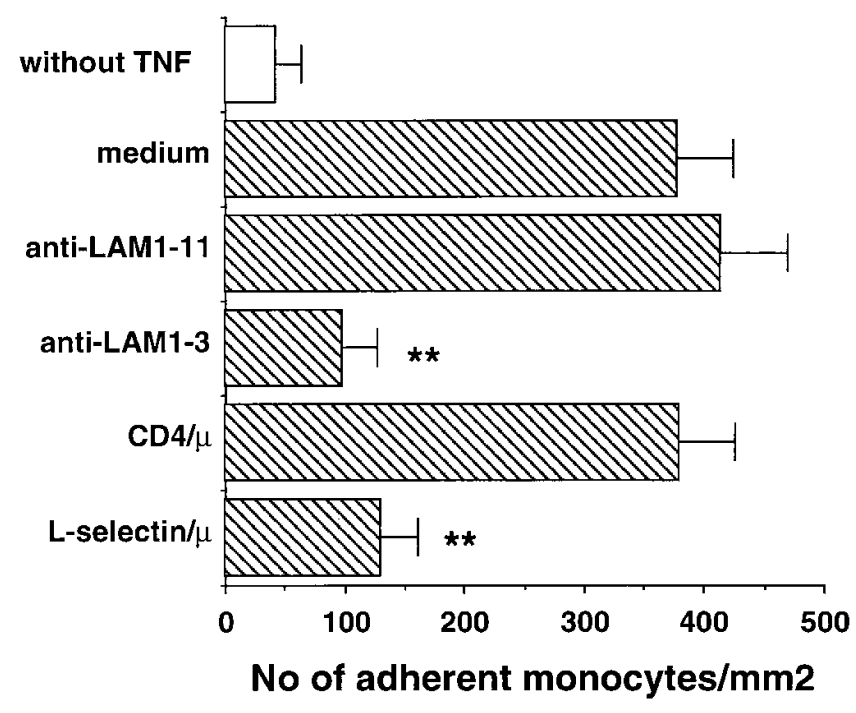

Figure 3. Monocyte adhesion to 8 -h TNF- $\alpha$-activated aortic endothelium under flow: inhibition by anti-L-selectin mAb LAM13 or L-selectin $/ \mu$ chimera. After 20 min of preincubation with $\mathrm{L}$-selectin $/ \mu$ or CD $4 / \mu$ chimera, BAEC monolayers were washed and inserted into the flow chamber. Untreated monocytes or monocytes preincubated in medium or with anti-LAM1-3 or anti-LAM1-11 mAb at $4^{\circ} \mathrm{C}$ were perfused across the monolayers at 1.8 dynes $/ \mathrm{cm}^{2}$ wall shear stress. Data are expressed as means \pm SD. Stably attached cells $(>20 \mathrm{~s})$ were counted in 13 random fields after 10 to $12 \mathrm{~min}$ of perfusion (rolling and transiently interacting cells were not included). Results are representative of four experiments. ${ }^{*}$ Statistically significant $(P<0.001)$ difference in adhesion relative to control.

tion before and after $2,4,6$, and $8 \mathrm{~h}$ of endothelial cell incubation with TNF- $\alpha(100 \mathrm{U} / \mathrm{ml})$. A time-dependent increase in monocyte binding was observed up to $6 \mathrm{~h}$ after the addition of TNF- $\alpha$ (Fig. 4 , solid circles). At $\geqslant 2 \mathrm{~h}$ of activation, monocyte binding to BAEC was inhibited by 48 to $68 \%$ with anti-LAM1-3 mAb (Fig. 4, open circles). With unstimulated BAEC, the inhibition observed with monocytes pretreated with anti-LAM1-3 did not reach statistical significance.

\section{Unstimulated and Cytokine-activated BAEC Express L-selectin Ligands}

L-selectin ligand expression by suspended BAEC was detected by flow cytometry, L-selectin/ $\mu$ being the probe and $\mathrm{CD} 4 / \mu$ being the control. L-selectin/ $\mu$ was found to bind to both unstimulated and cytokine-activated BAEC (Fig. 5, top, solid lines) whereas CD4/ $\mu$ did not (Fig. 5 , top, dotted lines). L-selectin/ $\mu$ binding to BAEC was completely inhibited by the presence of $5 \mathrm{mM}$ EDTA (Fig. 5, middle) or $100 \mu \mathrm{g} / \mathrm{ml}$ of function-blocking mAb anti-LAM1-3 or antiLAM1-4, which react with epitopes located on the lectin domain of L-selectin (Fig. 5, bottom). These latter results demonstrate the calcium dependence of L-selectin binding to aortic ligands and the involvement of the L-selectin lectin domain in this reaction.

Because activation of aortic endothelium with TNF- $\alpha$ induced a progressive increase in L-selectin-dependent monocyte adhesion (Fig. 4), L-selectin ligand expression by BAEC was followed over a 24 -h period of time. Sur- 


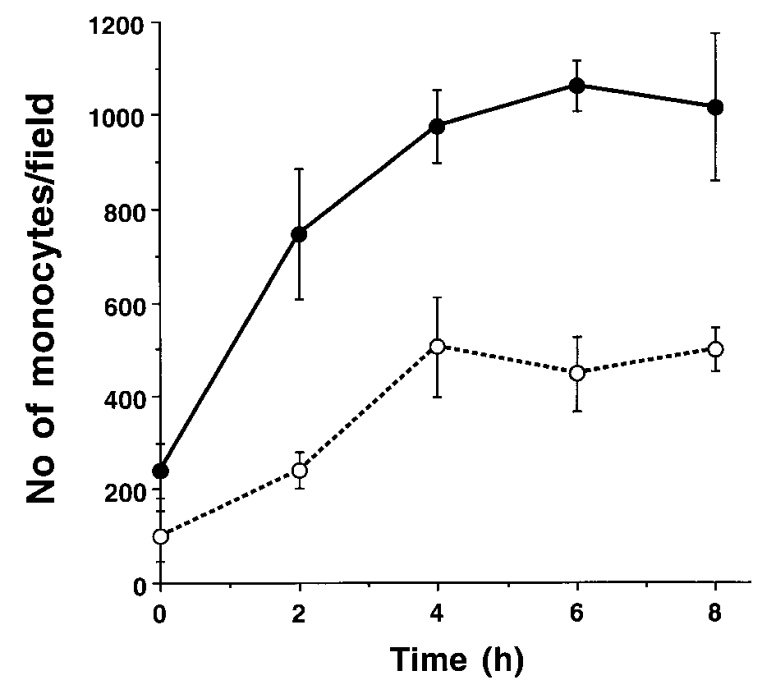

Figure 4. Kinetics of monocyte attachment to TNF- $\alpha$-activated aortic endothelium under rotation. Endothelial monolayers were stimulated with TNF- $\alpha(100 \mathrm{U} / \mathrm{ml})$ for $0-8 \mathrm{~h}$ at $37^{\circ} \mathrm{C}$ before the addition of monocytes. The L-selectin-dependent component of monocyte adhesion was determined using function-blocking $\mathrm{mAb}$ anti-LAM1-3. Adhesion assays were performed under rotation for $30 \mathrm{~min}$ at $4^{\circ} \mathrm{C}$. Solid circles represent adhesion of untreated monocytes. Open circles represent adhesion of monocytes pretreated with anti-LAM1-3 mAb. Data are expressed as means $\pm \mathrm{SD}$. Results are representative of two experiments.

prisingly, unstimulated BAEC or BAEC activated by TNF- $\alpha(100 \mathrm{U} / \mathrm{ml})$ for $2,4,6,8$, or $24 \mathrm{~h}$ were found to bind L-selectin $/ \mu$ in a similar fashion (Fig. 6).

\section{L-selectin Binding to BAEC: Different \\ Ligand Characteristics on Unstimulated and Cytokine-activated Endothelial Cells}

The role of proteoglycans in supporting L-selectin-endothelial interactions was investigated in experiments examining the effect of glycosidase or trypsin treatment on L-selectin binding to aortic endothelium. As illustrated in Fig. 7, L-selectin binding to unstimulated BAEC was not affected by hyaluronidase (bottom left) or chondroitinase $\mathrm{ABC}$ (middle right), whereas it was strongly inhibited by incubation with heparinase I (top right), heparinase I or III (not illustrated), and heparitinase II (middle left), and abrogated by cell exposure to trypsin (bottom right). Importantly, a quite different pattern was observed with BAEC activated by $8 \mathrm{~h}$ of incubation with TNF- $\alpha(100 \mathrm{U} / \mathrm{ml})$ (Fig. 8). Although trypsin treatment completely inhibited the reaction (Fig. 8, bottom right), activated BAEC exposure to heparinase I, heparitinase II, or heparitinase III only had moderate inhibitory effects on L-selectin binding (Fig. 8 , top right and middle). Thus, heparinase treatment induced a significantly higher decrease in L-selectin/ $\mu$ binding to unactivated BAEC (mean percentage of decrease $\pm \mathrm{SD} 42 \pm 17 \%, n=22)$ than to BAEC exposed for $8 \mathrm{~h}$ to TNF- $\alpha(26 \pm 14 \%, n=14, P=0.005)$. As observed with unstimulated cells, hyaluronidase and chondroitinase did not inhibit L-selectin binding to activated BAEC (bottom left and middle right).

Heparan sulfate proteoglycans are highly sulfated mole-

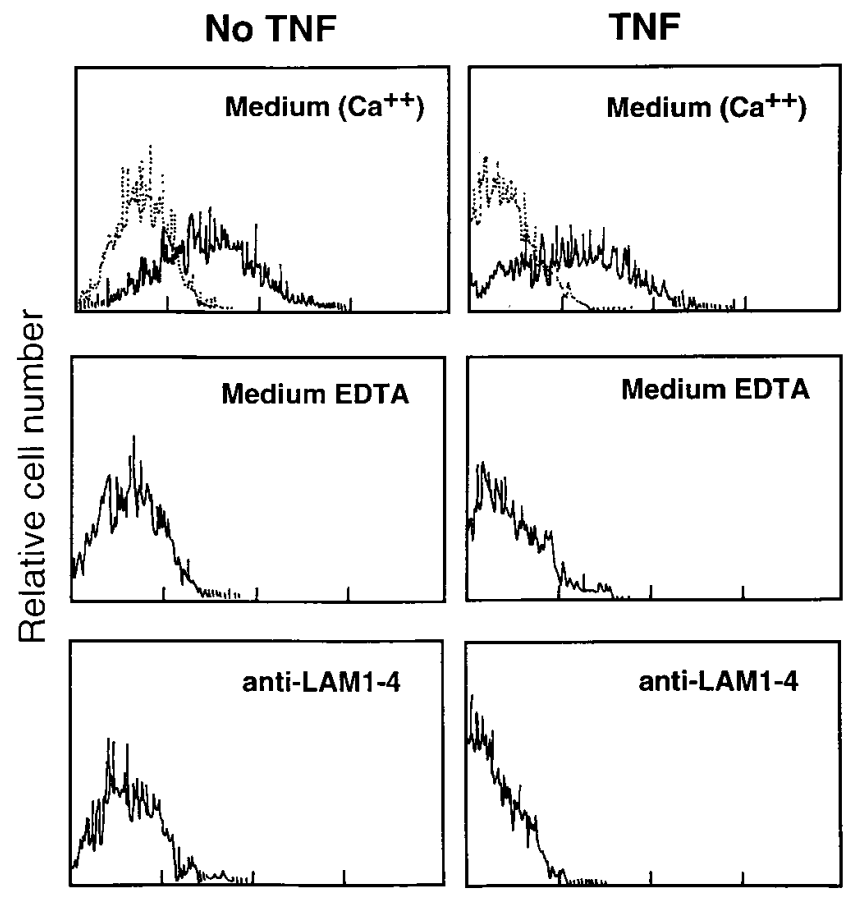

\section{Fluorescence intensity (log scale)}

Figure 5. Interaction of L-selectin with suspended aortic endothelial cells. Unactivated or TNF- $\alpha$-activated BAEC ( 8 h, $100 \mathrm{U} /$ $\mathrm{ml}$ ) were examined by indirect immunofluorescence analysis for the expression of L-selectin ligands. L-selectin/ $\mu$ was used as the probe (solid lines), and $\mathrm{CD} 4 / \mu$, an isotype-matched chimeric protein, was used as the control (dotted lines). The data are representative of three experiments.

cules, and sulfate residues are important for the function of several selectin ligands $(30,32,63,68,78)$. The role of sulfate residues in L-selectin-BAEC interactions was assessed by experiments using unactivated or TNF- $\alpha$-activated BAEC cultured for $24 \mathrm{~h}$ in the presence of $10 \mathrm{mM}$ sodium chlorate, an inhibitor of sulfate synthesis (7). As shown in Fig. 9, inhibition of sulfation inhibited most L-selectin binding to both unstimulated and cytokine-activated BAEC (bottom).

Cycloheximide treatment also strongly inhibited L-selectin binding, indicating that protein synthesis is required for ligand(s) expression by both unactivated and cytokineactivated endothelium (Fig. 9, middle).

Intact sialic acid residues are required for interactions between L-selectin and mucinlike glycoproteins such as GlyCAM-1, CD34, or PSGL-1. To assess whether sialic acid residues are involved in L-selectin binding to aortic endothelium, BAEC were pretreated for $45 \mathrm{~min}$ with $V$. cholerae $(750 \mathrm{mU} / \mathrm{ml})$ or A. ureafaciens neuraminidase $(200 \mathrm{mU} /$ $\mathrm{ml}$ ) before incubation with L-selectin/ $\mu$ chimera (Fig. 9, Vibrio Cholerae). Endothelial cell exposure to neuraminidase did not significantly affect L-selectin/ $\mu$ binding to unactivated BAEC. Thus, $63 \pm 15 \%(n=8)$ of BAEC treated with $V$. cholerae neuraminidase bound L-selectin/ $\mu$, whereas $47 \pm 26 \%(n=8)$ of untreated cells bound the chimera. Similarly, L-selectin $/ \mu$ binding to activated BAEC was not affected by neuraminidase. L-selectin/ $\mu$ 

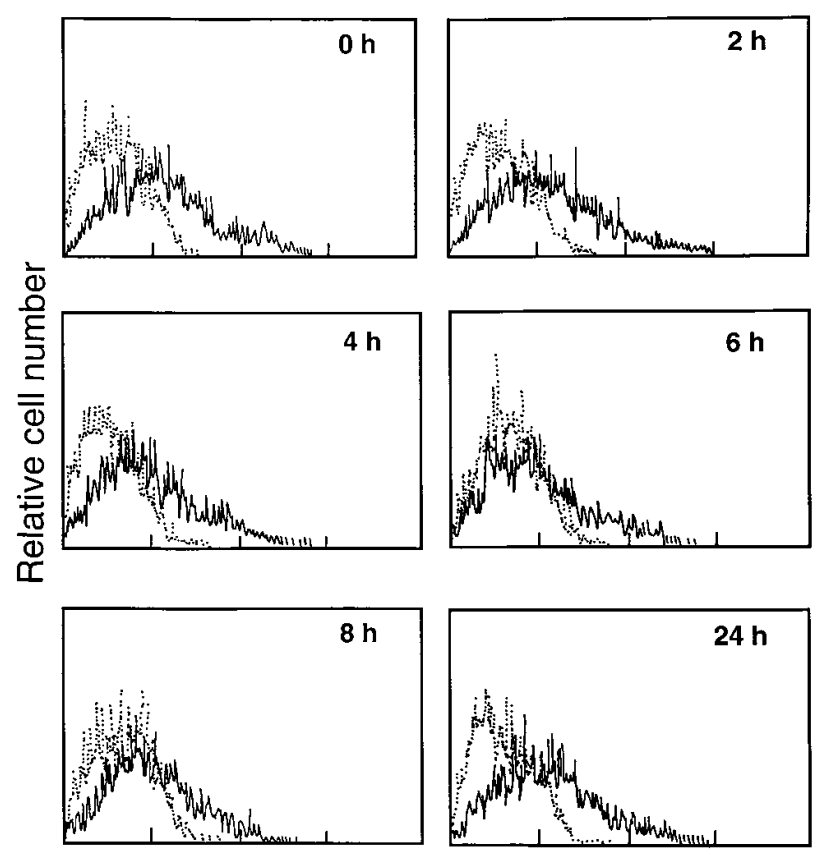

Fluorescence intensity (log scale)

Figure 6. Time course of aortic endothelial cell activation. Endothelial cells were activated with TNF- $\alpha(100 \mathrm{U} / \mathrm{ml})$. At the indicated times, indirect immunofluorescence analysis was performed with L-selectin $/ \mu$ (solid lines) and CD $4 / \mu$ (dotted lines). The data are representative of three experiments.

bound to $57 \pm 19 \%(n=6)$ of untreated cells and to $59 \pm$ $16 \%(n=6)$ of neuraminidase-treated cells. In contrast, monocyte exposure to $V$. cholerae neuraminidase (100 $\mathrm{mU} / \mathrm{ml}$ ) abolished L-selectin/ $\mu$ binding to monocyte PSGL-1 (not illustrated) (78).

\section{Role of Heparan Sulfates in Monocyte Adhesion to Cytokine-activated Endothelium}

The role of heparan sulfates in supporting monocyte attachment to TNF- $\alpha$-activated BAEC was studied by preincubating endothelial monolayers with heparinase I before monocyte addition. Adhesion assays performed under rotation after the addition of heparinase I indicated that heparan sulfates support monocyte attachment to 8-h TNF- $\alpha$-activated BAEC. Monocyte adhesion to cytokineactivated aortic endothelium was reduced by $36 \pm 11 \%$ (mean $\pm \mathrm{SD}, n=4, P<0.01$ ) using BAEC monolayers preexposed to heparinase I; BAEC pretreatment with $V$. cholerae neuraminidase $\left(750 \mathrm{mU} / \mathrm{ml}, 45 \mathrm{~min}\right.$ at $\left.37^{\circ} \mathrm{C}\right)$ did not significantly inhibit monocyte binding (inhibition of L-selectin/ $\mu$ binding $-8 \pm 6 \%, n=3$ ) (not illustrated). In control experiments in which monocytes were preincubated with anti-LAM1-3 mAb, monocyte attachment to TNF- $\alpha$-activated BAEC monolayers was inhibited by $64 \pm$ $18 \%(P<0.005)$.

Additional experiments were performed to examine the contribution of heparan sulfate proteoglycans in mediating primary monocyte adhesion to activated endothelial monolayers under flow. Monocyte attachment was very

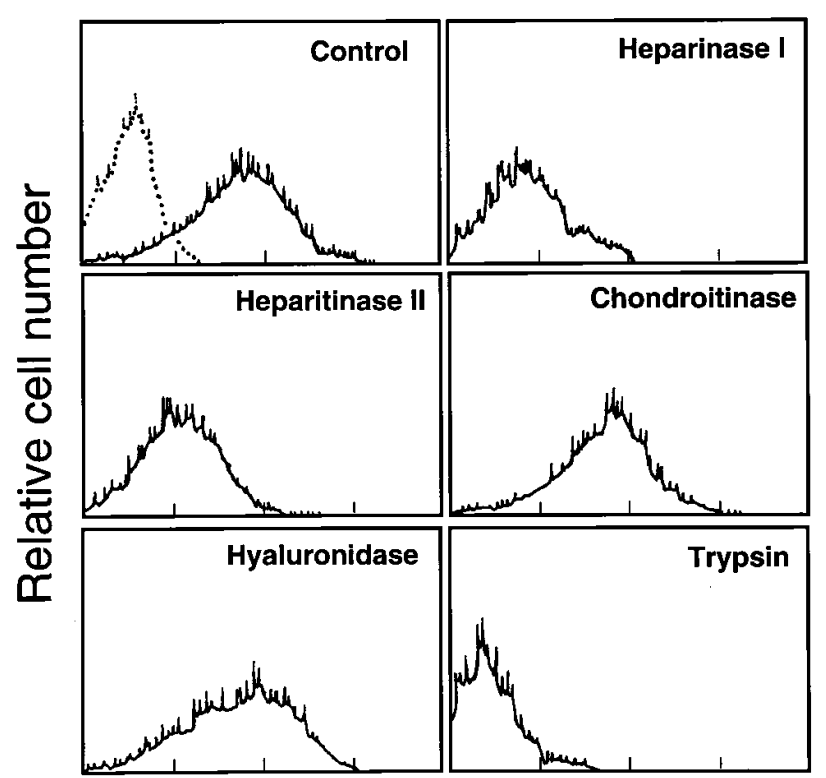

\section{Fluorescence intensity (log scale)}

Figure 7. Interaction of L-selectin with suspended aortic endothelial cells: effect of treating unstimulated BAEC with heparinase I, heparitinase II, chondroitinase $A B C$, hyaluronidase, or trypsin. Unactivated BAEC were examined by indirect immunofluorescence analysis with L-selectin $/ \mu$ (solid lines) and CD $4 / \mu$ (dotted lines). Identical results were obtained by treating BAEC with heparinase I, II, or III. The data are representative of six experiments. Percentages of BAEC that bound to L-selectin $/ \mu$ were as follows: control, $86 \%$; heparinase I, $54 \%$; heparitinase II, $56 \%$; chondroitinase, $89 \%$; hyaluronidase, $90 \%$; trypsin, $7 \%$. The background staining with $\mathrm{CD} 4 / \mu$ chimera was $<1 \%$.

significantly affected by the pretreatment of endothelial monolayers with heparinase I. At 1.8 dynes $/ \mathrm{cm}^{2}$, the total number of interacting monocytes (primary adhesion) during the first $5 \mathrm{~min}$ of the videotaped experiments was significantly reduced $(P<0.001)$. Thus, $304 \pm 43$ monocytes/ $\mathrm{mm}^{2}$ (mean $\pm \mathrm{SD}, n=3$ ) interacted with activated endothelial monolayers during this time, whereas $854 \pm 72$ interacting monocytes $/ \mathrm{mm}^{2}$ (mean $\pm \mathrm{SD}, n=3$ ) were observed with untreated endothelium. The number of stably adherent monocytes was also considerably inhibited by the pretreatment of activated endothelium with heparinase I. Adherent monocytes were counted during the last $2 \mathrm{~min}$ of the 12-min experiments. Stable monocyte adhesion was reduced by $88 \pm 6 \%$ (mean $\pm \mathrm{SD}, n=4, P<$ 0.001 ) after the pretreatment of endothelial monolayers with heparinase I (Fig. 10). Similar inhibition was obtained by treating monocytes with the function-blocking $\mathrm{mAb}$ anti-LAM1-3 (83 $\pm 8 \%)$, whereas the control anti-L-selectin $\mathrm{mAb}$ anti-LAM1-11 had no significant inhibitory effect.

\section{Discussion}

The following observations were made in this study: (a) L-selectin plays a major role in monocyte adhesion to TNF- $\alpha$-activated aortic endothelial cells; and (b) heparan 


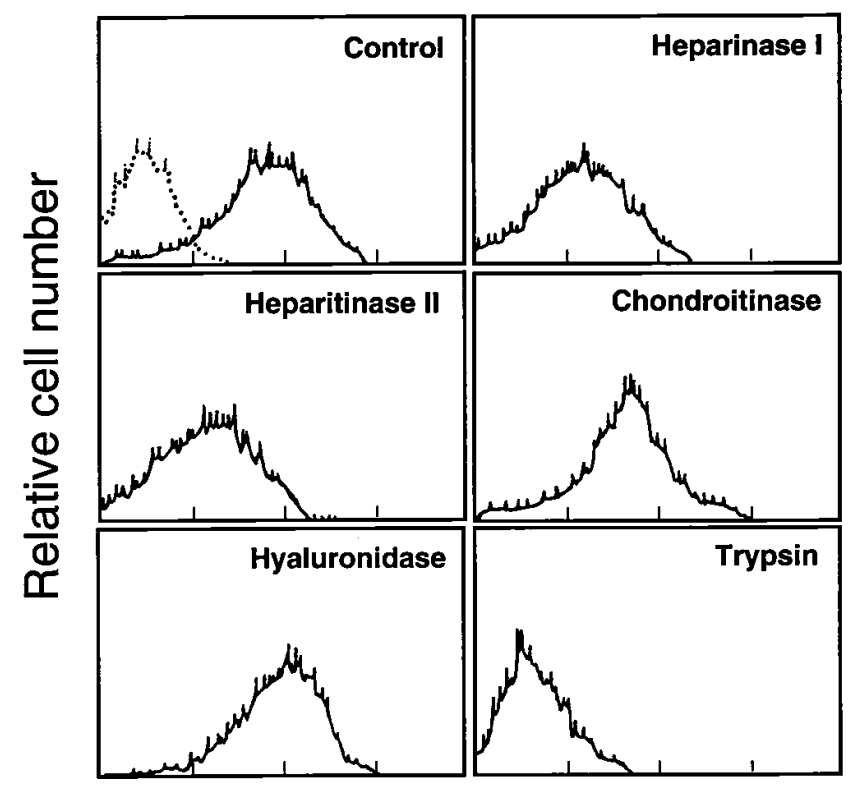

Fluorescence intensity (log scale)

Figure 8. Interaction of L-selectin with suspended aortic endothelial cells: effect of treating TNF- $\alpha$-activated BAEC ( 8 h, 100 $\mathrm{U} / \mathrm{ml}$ ) with heparinase I, heparitinase II, chondroitinase ABC, hyaluronidase, or trypsin. Unactivated BAEC were examined by indirect immunofluorescence analysis with L-selectin/ $\mu$ (solid lines) and $\mathrm{CD} 4 / \mu$ (dotted lines). Identical results were obtained by treating BAEC with heparinase I, II, or III. The data are representative of six experiments. Percentages of BAEC that bound to L-selectin/ $\mu$ are as follows: control, $87 \%$; heparinase I, 39\%; heparitinase II, $47 \%$; chondroitinase, $89 \%$; hyaluronidase, $82 \%$; trypsin, $4 \%$.

sulfate proteoglycans and possibly other protein-based ligands function as arterial counterreceptors for monocyte L-selectin. These findings provide novel information on the molecular mechanisms of monocyte attachment to activated arterial endothelium, a key cellular reaction in the initial lesion of atherosclerosis.

Cell adhesion assays performed under rotation have previously shown that L-selectin plays a major role in initiating monocyte attachment to cytokine-activated venous endothelium in vitro (76). Subsequently, experiments made with an in vitro flow system have confirmed that L-selectin has a crucial role in initiating monocyte attachment, supporting monocyte rolling, and facilitating $\alpha 4 \beta 1$-integrindependent arrest $(48,49)$. Thus, interactions between monocytes and venous endothelial cells seem to involve L-selectin-dependent monocyte rolling on the endothelial cell surface, followed by sequential involvement of $\beta 1$ integrin, $\beta 2$ integrin, and CD31 (PECAM-1) in subsequent steps of monocyte migration into tissues. In this study, we observed under rotating conditions that L-selectin plays a major role in mediating monocyte attachment to activated arterial endothelium. Involvement of L-selectin was demonstrated by experiments showing that adhesion-blocking anti-L-selectin mAbs LAM1-3 and LAM1-4 had the capacity to inhibit monocyte binding to activated aortic endothelium, whereas this reaction was not inhibited by anti-LAM1-11 and anti-LAM1-10 mAbs, which recognize

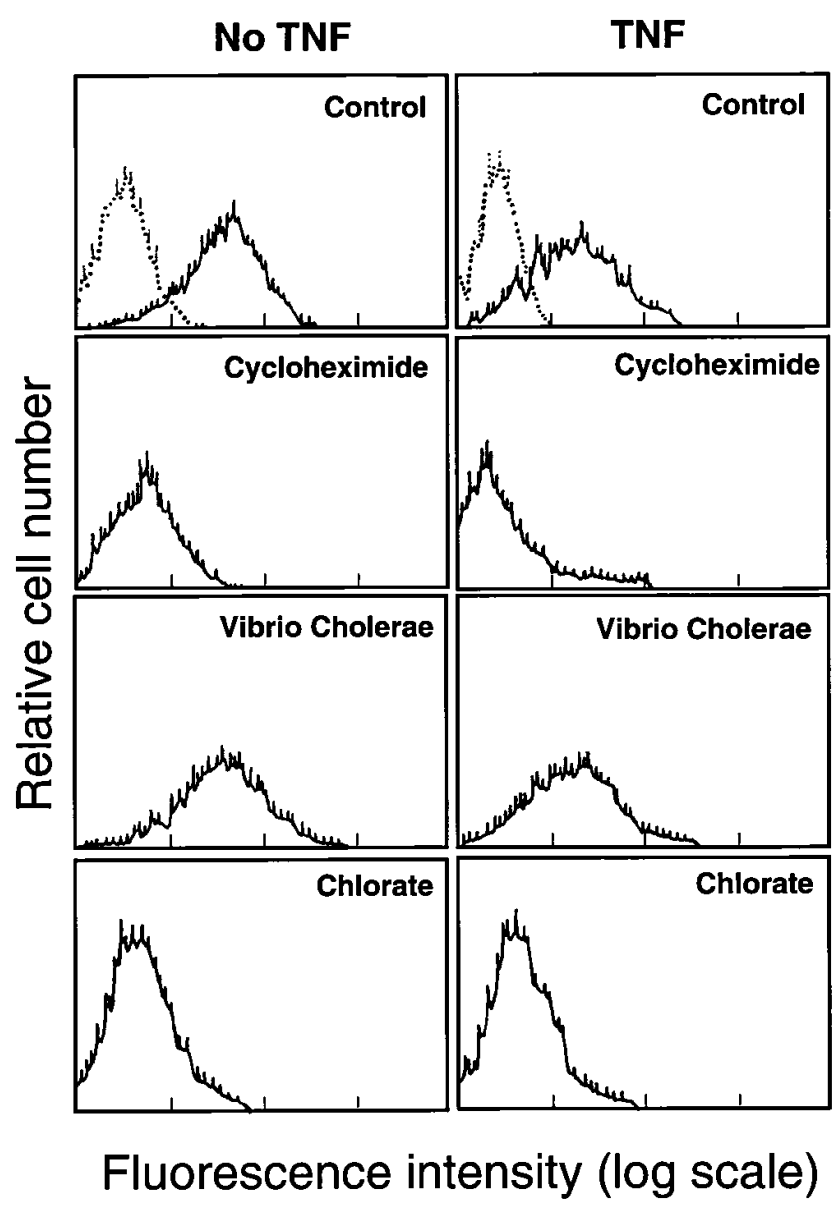

Figure 9. Interaction of L-selectin with suspended aortic endothelial cells: effect of treating unstimulated or TNF- $\alpha$-activated BAEC $(6 \mathrm{~h}, 100 \mathrm{U} / \mathrm{ml})$ with cycloheximide $(10 \mu \mathrm{g} / \mathrm{ml})$, V. cholerae neuraminidase $(750 \mathrm{U} / \mathrm{ml})$, or sodium chlorate $(10 \mathrm{mM}, 24$ h). BAEC were examined by indirect immunofluorescence analysis with L-selectin $/ \mu$ (solid lines) and $\mathrm{CD} 4 / \mu$ (dotted lines). The data are representative of six experiments. Percentages of unactivated BAEC that bound to L-selectin $/ \mu$ are as follows: control, $86 \%$; cycloheximide, $22 \%$; V. cholerae, $91 \%$; chlorate, $13 \%$. Percentages of TNF- $\alpha$-activated BAEC that bound to L-selectin $/ \mu$ are as follows: control, $77 \%$; cycloheximide, $11 \%$; V. cholerae, $89 \%$; chlorate, $17 \%$.

domains of L-selectin not involved in cell adhesion (Fig. 1). Further support for the notion that monocytes are attached to arterial endothelium via L-selectin was provided by experiments showing the capacity of L-selectin/ $\mu$ to inhibit monocyte-endothelial interactions (Fig. 2). Equivalent inhibitions were obtained by preincubating activated aortic cell monolayers with $\mathrm{L}$-selectin/ $\mu$ or by treating monocytes with mAb LAM1-3, indicating that L-selectin/ $\mu$ had the capacity to completely inhibit L-selectin-dependent cell adhesion. Under the same conditions, CD4/ $\mu$ had no inhibitory effect on monocyte binding to activated aortic endothelium (Fig. 2).

The cellular and molecular bases of monocyte attachment were further analyzed using an in vitro flow chamber using function-blocking $\mathrm{mAb}$ and chimeric molecules. $\mathrm{Ob}-$ servations made in videomicroscopy experiments showed that freely flowing monocytes abruptly halted on 8-h TNF- 


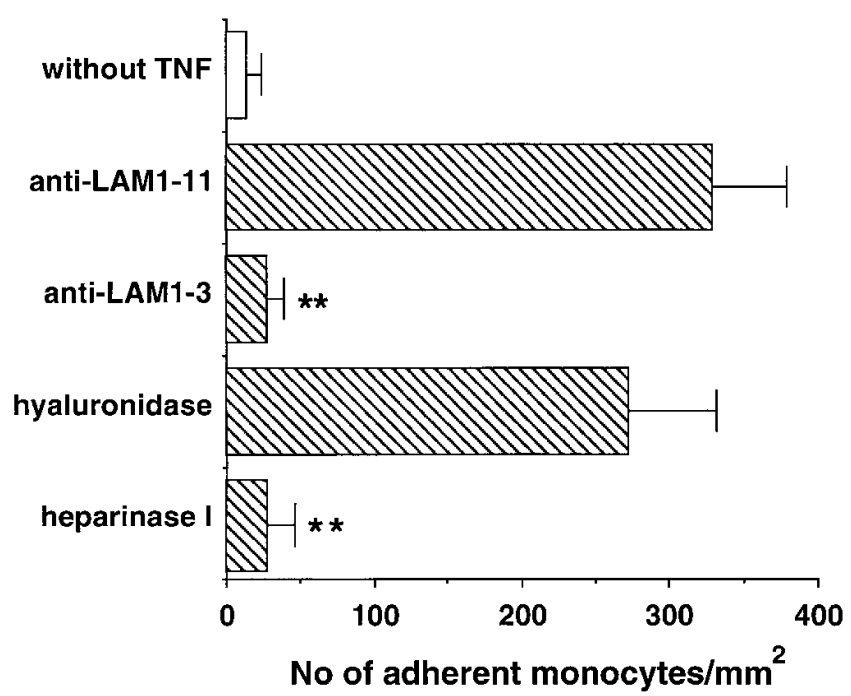

Figure 10. Inhibition of monocyte adhesion to 8 -h TNF- $\alpha$-activated endothelium under flow (wall shear stress estimated at 1.8 dynes $/ \mathrm{cm}^{2}$ ). Endothelial monolayers were activated for $8 \mathrm{~h}$ with TNF- $\alpha(100 \mathrm{U} / \mathrm{ml})$, washed, and then preincubated for $45 \mathrm{~min}$ at $37^{\circ} \mathrm{C}$ with heparinase I $(1,600 \mathrm{mU} / \mathrm{ml})$ or hyaluronidase $(200$ $\mathrm{mU} / \mathrm{ml})$. The adhesion assay was performed in a flow chamber, and adherent monocytes were counted as described in the legend to Fig. 3. Data are expressed as means \pm SD. Results are representative of three experiments. ${ }^{*} P<0.001$.

$\alpha$-activated aortic endothelium primarily through L-selectin. mAb blockade of L-selectin inhibited by $\sim 80 \%$ monocyte attachment to TNF- $\alpha$-activated endothelium (Fig. 3). These observations are consistent with those describing, under flow, monocyte interactions with 6-h TNF- $\alpha$-activated human umbilical vein endothelial cells (49), and they are the first to show that L-selectin mediates monocyte attachment to activated aortic endothelium. Because recent studies reported that neutrophils can roll on already adherent neutrophils $(8,22,78)$, L-selectin-mediated monocyte primary adhesion to activated endothelium was examined during the first $5 \mathrm{~min}$ of each experiment, when the number of stably adherent monocytes is low. Careful analysis of the video records showed that flowing monocytes occasionally slowed down and arrested on adherent monocytes, facilitating their attachment to activated endothelium. These interactions were discarded for quantitative analysis. Only single-cell interactions with activated endothelium were taken into consideration. The strong inhibition of monocyte attachment to activated endothelium induced by the pretreatment of endothelium with L-selectin/ $\mu$ further indicated that $L$-selectin interaction with endothelial ligand(s) is an important mechanism of monocyte recruitment at the vascular endothelial cell surface.

Interestingly, studies with adhesion-blocking $\mathrm{mAbs}$ have shown that L-selectin cooperates with VCAM-1 to support monocyte attachment to activated arterial endothelium. Anti-VCAM-1 mAb HAE-2 (73) inhibited 38\% of monocyte adhesion (Fig. 1). The induction of VCAM-1 by TNF- $\alpha$ observed here is consistent with results from earlier studies reporting expression of that receptor on aortic endothelium in acute rejection of rabbit cardiac allograft
(82) or after balloon injury of the aorta (81). In addition, several studies have reported that VCAM-1 is expressed on atherosclerotic lesions, suggesting that VCAM-1 could play a critical role in regulating monocyte entry into the arterial wall $(20,59)$. Because this study has identified L-selectin as a major mediator of monocyte attachment to cytokine-activated arterial endothelium, it will be important to assess in subsequent work the extent to which L-selectin is also involved in regulating monocyte entry into atherosclerotic lesions. Clearly, a detailed elucidation of the molecular mechanisms involved in monocyte attachment to the arterial wall will be required to understand how atherosclerotic plaques are formed and to generate drugs that may have the capacity to inhibit the formation of these lesions.

Adhesion-blocking $\mathrm{mAb}$ studies have previously suggested that an inducible ligand for monocytes is expressed on human umbilical vein endothelial cells upon activation with TNF- $\alpha(34,48,49,76)$. Other investigators have reported that additional endothelia can also express cytokine-inducible ligands (14). Here, the progressive increase in L-selectin-mediated monocyte adhesion observed after activation of endothelial cells with TNF- $\alpha$ suggested again that inducible ligands for L-selectin are expressed on activated aortic endothelial cells (Fig. 4). The nature of these ligands was probed by experiments examining the binding of soluble recombinant L-selectin/ $\mu$ to live endothelial cells. Considering that multivalency could be an important factor in selectin function (65), we used a decameric form of L-selectin instead of a dimeric chimera to improve the detection of L-selectin ligands. Surprisingly, soluble L-selec$\operatorname{tin} / \mu$ was also found to bind to unactivated aortic endothelial cells (Fig. 5). This result was unexpected because unactivated endothelium supported only little monocyte binding (Figs. 1-3). The specificity of L-selectin/ $\mu$ binding to aortic cells was established using EDTA or functionblocking mAb anti-LAM1-3 or anti-LAM1-4, which completely inhibited L-selectin binding, whereas control anti$\mathrm{L}$-selectin $\mathrm{mAbs}$ had no effect on this reaction. Activation of endothelial cells by TNF- $\alpha$ had little influence on L-selectin/ $\mu$ binding (Figs. 5 and 6). Endothelial cell treatment with various glycosaminoglycan-cleaving enzymes demonstrated that ligands expressed on both unactivated and activated aortic endothelium were sensitive to heparinase I and heparitinase II (Figs. 7 and 8). In addition, binding of L-selectin to aortic endothelium was completely abolished by trypsin, which indicates that L-selectin binds to heparan sulfate chains attached to protein in the form of proteoglycans. Importantly, the reactivity of L-selectin with cytokineactivated aortic cells was only partially susceptible to heparinase I and heparitinase II digestion. This latter observation suggests that cytokine activation could induce the expression of additional ligands, distinct from heparan sulfate proteoglycans that interact with L-selectin to support monocyte adhesion. Alternatively, TNF- $\alpha$ could increase monocyte adhesion to endothelium by modifying heparan sulfate proteoglycan glycosylation or sulfation. This mechanism could induce expression of L-selectin-binding sequences responsible for high affinity interactions between L-selectin and cytokine-activated aortic cells; these sequences would not be expressed on unstimulated arterial endothelium. An additional option is that the arterial endothelial 
response observed after TNF- $\alpha$ activation occurs with preexisting L-selectin ligands. In this scenario, unstimulated aortic endothelial cells have dispersed L-selectin ligands on their surface, which can bind L-selectin/ $\mu$ but cannot support monocyte adhesion; in contrast, on the surface of activated endothelial cells, L-selectin ligands could form patches capable of both L-selectin/ $\mu$ and monocyte binding. Further studies will be needed to investigate these possibilities.

The lack of significant change in L-selectin/ $\mu$ binding to aortic endothelial cells after TNF- $\alpha$ activation does not preclude the existence of inducible ligands for L-selectin (Figs. 5 and 6). Thus, the increase in L-selectin-dependent binding of monocytes observed after BAEC activation could be mediated by ligands that react with high affinity with L-selectin but are expressed at low density at the cell surface. One can speculate that heparan sulfate proteoglycans function as low affinity L-selectin ligands that attract monocytes at the vascular cell surface (coreceptor function) and direct them to less abundant high affinity receptors. This process could be analogous to the one that regulates the presentation of FGF by multimeric heparan sulfate proteoglycans to high affinity FGF receptor (69). In addition, the capacity of heparan sulfate proteoglycans to present cytokines to attracted monocytes may provide adhesion-inducing signals that regulate subsequent steps of adhesion $(66,79,80)$. As discussed above, the partial susceptibility of L-selectin ligands to heparin lyases suggests that additional ligands for L-selectin could be expressed by $\mathrm{TNF}-\alpha$-activated endothelium. Heparan sulfate proteoglycans could have an important role in supporting monocyte rolling along endothelium, whereas less abundant high affinity ligands could be required to allow monocyte arrest. The increase in L-selectin-dependent monocyte adhesion observed after activation of BAEC with TNF- $\alpha$ (Fig. 4) could be explained by the expression of ligands not present on unactivated BAEC.

E-selectin is an inducible high affinity ligand that could cooperate with heparan sulfate proteoglycans to mediate monocyte attachment to activated endothelial cells. Expression of this adhesion molecule has been observed on endothelial cells lining atherosclerotic lesions and in rabbits fed a hypercholesterolemic diet (24). PSGL-1 interacts with E-selectin to mediate monocyte attachment to endothelial cells $(6,61,78)$. In addition, L-selectin expressed by human neutrophils binds to E-selectin through a carbohydrate ligand expressed by the lectin domain of L-selectin (62). This latter interaction was studied in a control shear adhesion assay by Lawrence et al. (41) and others (61), who observed an L-selectin-dependent neutrophil tethering to E-selectin. E-selectin and heparan sulfate could cooperate to mediate monocyte attachment to activated endothelium. Further studies will be required to determine if additional ligands distinct from E-selectin could be involved in initiating monocyte attachment through L-selectin to activated endothelium. Finally, leukocyte recruitment in inflammatory lesions is not only dependent on the interaction of neutrophils with endothelial cells but could be considerably increased by the rolling of leukocytes on already adherent leukocytes $(3,8,25,60,73)$. Several studies demonstrated that a major part of leukocyte-leukocyte interactions is regulated by L-selectin and its ligand PSGL-1
$(8,28,60,78,87)$. Thus, L-selectin is critically involved in promoting leukocyte recruitment at the site of inflammation by its capacity to regulate leukocyte interactions with endothelial cell surface and leukocyte attachment to already adherent leukocytes.

The strong inhibition by cycloheximide of L-selectin ligand expression by unstimulated and cytokine-activated aortic endothelium indicated that protein synthesis is required for L-selectin binding (Fig. 9). Heparan sulfate proteoglycans involved in L-selectin binding are probably renewed in a continuous fashion. Earlier reports on heparan sulfate proteoglycans have indicated that these species have half-lives of between 3 and $8 \mathrm{~h}$ at the endothelial cell surface, removal from the cell surface resulting from proteoglycan endocytosis and shedding into the extracellular space (94).

The role of sulfates on L-selectin binding to aortic endothelium was evaluated because sulfate residues were found to be necessary for the function of several selectin ligands $(9,11,29,30,40,63,68,88,93)$. Inhibition of ATPsulfurylase by chlorate (7) prevented most soluble L-selectin binding, demonstrating that sulfation is critical for the interaction of L-selectin with arterial endothelial cell ligands (Fig. 9). Inhibition of sulfation could abolish the interaction of L-selectin with highly sulfated molecules, like heparan sulfate, thereby inhibiting most L-selectin reactivity with BAEC. It is also possible that other unidentified sulfated ligands interact with L-selectin to support monocyte adhesion to activated aortic endothelium.

Several glycoprotein ligands for selectins require sialic acid residues for function. In the present study, digestion of activated and unactivated aortic endothelium with neuraminidase did not affect significantly L-selectin binding or monocyte attachment, under rotation, to aortic endothelium. In this regard, aortic endothelium L-selectin ligands behave quite differently from GlyCAM-1, CD34, or PSGL-1 $(9,18,31,40,54,67,86)$. The lack of effect of neuraminidase treatment on monocyte adhesion and on L-selectin/ $\mu$ binding to BAEC suggests that sialic acid residues could not be essential for L-selectin ligand function. However, this result must be cautiously interpreted because we cannot exclude that a subset of sialic acid residues resistant to enzymatic cleavage could play a role in L-selectin binding.

Norgard-Sumnicht et al. $(57,58)$ have previously reported the presence of heparan sulfate in a calf pulmonary artery endothelial cell line (American Type Culture Collection CCL 209). However, staining of this cell line with an L-selectin/IgG1 heavy chain chimera revealed the presence of an intracellular pool of heparan sulfate but no significant surface expression of the ligand (57). Here, using a decameric L-selectin chimera, we show that heparan sulfate proteoglycans are expressed at the surface of aortic endothelial cells and play a major role in L-selectin-dependent attachment of monocytes to TNF- $\alpha$-activated aortic endothelium (Fig. 10). Moreover, endothelial monolayer treatment with heparinase I inhibited monocyte adhesion to activated endothelial monolayers. Future studies will be aimed at identifying and characterizing heparan sulfate proteoglycans involved in L-selectin endothelial cell interactions and the additional ligand(s) that may cooperate with heparan sulfate proteoglycans to support monocyte adhesion. It is possible that heparan sulfate expressed by arte- 
rial endothelium has L-selectin-specific recognition sequences that are not present on heparan sulfate extracted from bovine intestinal mucosa. Indeed, Diamond et al. (21), using a flow system, did not observe interactions between L-selectin and bovine intestinal mucosa heparan sulfate.

The in vitro observation that heparan sulfate proteoglycans are ligands for L-selectin and mediate monocyte attachment to activated aortic endothelium needs to be extended by in vivo studies. The identification of specific sequences responsible for the interaction of L-selectin with sulfated glycosaminoglycans may lead to the preparation of heparan sulfate analogues with the potential of inhibiting pathological leukocyte recruitment in inflammatory diseases. The ability of some heparin oligosaccharides to inhibit leukocyte migration at sites of inflammation suggests that this approach might have therapeutic potential $(56,58)$.

The authors are grateful to Dr. Philippe Schneider, Dr. Jean-Daniel Tissot, and the staff of the Centre de Transfusion Sanguine at Lausanne for providing buffy coats. We thank Dr. Jacques-Antoine Haeffliger for providing BAEC, and Drs. André Traunecker and Klaus Karjalainen for providing CD4 and IgM heavy chain DNAs.

This work was supported by grant 31-43235.95 from the Swiss National Foundation for Scientific Research, the Marie Heim-Vögtlin Foundation, and the Emma Muschamp Foundation.

Received for publication 4 June 1996 and in revised form 15 October 1996.

\section{References}

1. Adams, D.H., and S. Shaw. 1994. Leucocyte-endothelial interactions and regulation of leukocyte migration. Lancet. 343:831-836.

2. Alon, R., T. Feizi, C.-T. Yuen, R.C. Fuhlbrigge, and T.A. Springer. 1995 Glycolipid ligands for selectins support leukocyte tethering and rolling under physiologic flow conditions. J. Immunol. 154:5356-5366.

3. Alon, R., R.L. Fuhlbrigge, E.B. Finger, and T.A. Springer. 1996. Interactions through L-selectin between leukocytes and adherent leukocytes nucleate rolling adhesions on selectins and VCAM-1 in shear flow. J. Cell Biol. 135:849-865.

4. Arbones, M.L., D.C. Ord, K. Ley, H. Radich, C. Maynard-Curry, D.J. Cappon, and T.F. Tedder. 1994. Lymphocyte homing and leukocyte rolling and migration are impaired in L-selectin (CD62L) deficient mice. Immunity. 1:247-260.

5. Aruffo, A., W. Kolanus, G. Walz, P. Fredman, and B. Seed. 1991. CD62/Pselectin recognition of myeloid and tumor cell sulfatides. Cell. 67:35-44.

6. Asa, D., L. Raycroft, L. Ma, P.A. Aeed, P.S. Kaytes, A.P. Elhammer, and J.-G. Geng. 1995. The P-selectin glycoprotein ligand functions as a common human leukocyte ligand for P-and E-selectins. J. Biol. Chem. 270: $11663-11670$.

7. Baeuerle, P.A., and W.B. Huttner. 1986. Chlorate-a potent inhibitor of protein sulfation in intact cells. Biochem. Biophys. Res. Commun. 141: 870-877.

8. Bargatze, R., S. Kurk, E. Butcher, and M. Jutila. 1994. Neutrophils roll on adherent neutrophils bound to cytokine-induced endothelial cells via L-selectin on the rolling cells. J. Exp. Med. 180:1785-1792.

9. Baumhueter, S., M.S. Singer, W. Henzel, S. Hemmerich, M. Renz, S.D. Rosen, and L.A. Lasky. 1993. Binding of L-selectin to the vascular sialomucin CD34. Science (Wash. DC). 262:436-438.

10. Baumhueter, S., N. Dybdal, C. Kyle, and L.A. Lasky. 1994. Global vascular expression of murine CD34, a sialomucin-like endothelial ligand for L-selectin. Blood. 84:2554-2565.

11. Berg, E.L., L.M. McEvoy, C. Berlin, R.F. Bargatze, and E.C. Butcher. 1993. L-selectin mediated lymphocyte rolling on MadCAM-1. Nature (Lond.). 366:695-698.

12. Bevilacqua, M.P., S. Stengelin, M.A. Gimbrone, Jr., and B. Seed. 1989. Endothelial leukocyte adhesion molecule 1: an inducible receptor for neutrophils related to complement regulatory proteins and lectins. Science (Wash. DC). 243:1160-1164.

13. Bevilacqua, M.P., J.S. Pober, D.L. Mendrick, R.S. Cotran, and M.A. Gimbrone, Jr. 1987. Identification of an inducible endothelial-leukocyte adhesion molecule. Proc. Natl. Acad. Sci. USA. 84:9238-9243.

14. Brady, H.R., O. Spertini, W. Jimenez, B.M. Brenner, P.A. Marden, and T.F. Tedder. 1992. Neutrophils, monocytes and lymphocytes bind to cytokine-activated kidney glomerular endothelial cells through L-selectin (LAM-1) in vitro. J. Immunol. 149:2437-2444.

15. Brustein, M., G. Kraal, R.E. Mebius, and S.R. Watson. 1992. Identification of a soluble form of a ligand for the lymphocyte homing receptor. J. Exp. Med. 176:1415-1419.

16. Carlos, T.C., and J.M. Harlan. 1994. Leukocyte-endothelial adhesion molecules. Blood. 84:2068-2101.

17. Cooke, R.M., R.S. Hale, S.G. Lister, G. Shah, and M.P. Weir. 1994. The conformation of the sialyl Lewis $\mathrm{X}$ ligand changes upon binding to E-selectin. Biochemistry. 33:10591-10596.

18. Crommie, D., and S.D. Rosen. 1995. Biosynthesis of GlyCAM-1, a mucinlike ligand for L-selectin. J. Biol. Chem. 270:22614-22624.

19. Crottet, P., Y.J. Kim, and A. Varki. 1996. Subsets of sialylated, sulfated mucins of diverse origins are recognized by L-selectin: lack of evidence for unique oligosaccharide sequence mediating binding. Glycobiology. 6 : 191-208.

20. Cybulsky, M.I., and M.A. Gimbrone. 1991. Endothelial expression of a mononuclear leukocyte adhesion molecule during atherogenesis. Science (Wash. DC). 251:788-791.

21. Diamond, M.S., R. Alon, C.A. Parkos, M.T. Quinn, and T.A. Springer 1995. Heparin is an adhesive ligand for the leukocyte integrin Mac-1 (CD11b/CD18). J. Cell Biol. 130:1473-1482.

22. Finger, E.B., K.D. Puri, R. Alon, M.B. Lawrence, U.H. von Andrian, and T.A. Springer. 1996. Adhesion through L-selectin requires a threshold hydrodynamic shear. Nature (Lond.). 379:266-269.

23. Foxall, C., S.R. Watson, D. Dowbenko, C. Fennie, L.A. Lasky, M. Kiso, A Hasegawa, D. Asa, and B.K. Brandley. 1992. The three members of the selectin receptor family recognize a common carbohydrate epitope, the sialyl Lewisx oligosaccharide. J. Cell Biol. 117:895-902.

24. Frostegard, J., R. Wu, A. Haegerstrand, M. Patarroyo, A. Lefvert, and J. Nilsson. 1993. Mononuclear leukocytes exposed to oxidized low density lipoprotein secrete a factor that stimulates endothelial cells to express adhesion molecules. Atherosclerosis. 103:213-219.

25. Fuhlbrigge, R.L., R. Alon, K.D. Puri, J.B. Lowe, and T.A. Springer. 1996 Sialylated, fucosylated ligands for L-selectin expressed on leukocytes mediate tethering and rolling adhesions in physiologic flow conditions. $J$. Cell Biol. 135:849-865.

26. Geng, J.G., M.P. Bevilacqua, K.L. Moore, T.M. McIntyre, S.M. Prescott, J.M. Kim, G.A. Bliss, G.A. Zimmerman, and R.P. McEver. 1990. Rapid neutrophil adhesion to activated endothelium mediated by GMP-140. Nature (Lond.). 343:757-760.

27. Griffin, J.D., O. Spertini, T.J. Ernst, M.P. Belvin, H.B. Levine, Y. Kanakura, and T.F. Tedder. 1990. GM-CSF and other cytokines regulate surface expression of the leukocyte adhesion molecule-1 on human neutrophils, monocytes, and their precursors. J. Immunol. 145:576-584.

28. Guyer, D.A., K.L. Moore, E.B. Lynam, C.M.G. Schammel, S. Rogelj, R.P. McEver, and L.A. Sklar. 1996. P-selectin glycoprotein ligand-1 (PSGL-1) is a ligand for L-selectin in neutrophil aggregation. Blood. 88:2415-2421.

29. Hemmerich, S., C.R. Bertozzi, H. Leffler, and S.D. Rosen. 1994. Identification of the sulfated monosaccharides of GlyCAM-1, an endothelialderived ligand for L-selectin. Biochemistry. 33:4820-4829.

30. Hemmerich, S., E.C. Butcher, and S.D. Rosen. 1994. Sulfation-dependent recognition of high endothelial venules (HEV)-ligands by L-selectin and MECA 79, an adhesion-blocking monoclonal antibody. J. Exp. Med. 180: 2219-2226.

31. Hemmerich, S., H. Leffler, and S.D. Rosen. 1995. Structure of the o-glycans in GlyCAM-1, an endothelial-derived ligand for L-selectin. J. Biol. Chem. 270:12035-12047.

32. Imai, Y., L.A. Lasky, and S.D. Rosen. 1993. Sulphation requirement for GlyCAM-1, an endothelial ligand for L-selectin. Nature (Lond.). 361: $555-557$.

33. Jacob, G.S., C. Kirmaier, S.Z. Abbas, S.C. Howard, C.N. Steininger, J.K. Welply, and P. Scudder. 1995. Binding of sialyl Lewis x to E-selectin as measured by fluorescence polarization. Biochemistry. 34:1210-1217.

34. Jones, D.A., C.W. Smith, L.J. Picker, and L.V. Mcintire. 1996. Neutrophil adhesion to 24-hour IL-1 stimulated endothelial cells under flow conditions. J. Immunol. 157:858-863.

35. Kansas, G., K. Ley, J. Munro, and T. Tedder. 1993. Regulation of leukocyte rolling and adhesion to high endothelial venules through the cytoplasmic domain of L-selectin. J. Exp. Med. 177:833-838.

36. Krause, D.S., M.J. Fackler, C.I. Civin, and M. Stratford. 1996. CD34: structure, biology, and clinical utility. Blood. 87:1-13.

37. Larsen, E., E.A. Celi, G.E. Gilbert, B.C. Furie, J.K. Erban, R. Bonfanti, D.D. Wagner, and B. Furie. 1989. PADGEM protein: a receptor that mediates the interaction of activated platelets with neutrophils and monocytes. Cell. 59:305-312.

38. Lasky, L. 1995. Selectin-carbohydrate interactions and the initiation of the inflammatory response. Annu. Rev. Biochem. 64:113-139.

39. Lasky, L.A. 1992. Selectins: interpreters of cell-specific carbohydrate information during inflammation. Science (Wash. DC). 258:964-968.

40. Lasky, L.A., M.S. Singer, D. Dowbenko, Y. Imai, W.J. Henzel, C. Grimley, C. Fennie, N. Gillett, S.R. Watson, and S.D. Rosen. 1992. An endothelial ligand for L-selectin is a novel mucin-like molecule. Cell. 69:927-938.

41. Lawrence, M.B., D.F. Bainton, and T.A. Springer. 1994. Neutrophil tethering to and rolling on E-selectin are separatable by requirement for L-selec- 
tin. Immunity. 1:137-145.

42. Ley, K., P. Gaehtgens, C. Fennie, M.S. Singer, L.A. Lasky, and S.D. Rosen. 1991. Lectin-like cell adhesion molecule 1 mediates leukocyte rolling in mesenteric venules in vivo. Blood. 77:2553-2555.

43. Ley, K., D.C. Bullard, M.L. Arbonés, R. Bosse, D. Vestweber, T.F. Tedder, and A.L. Beaudet. 1995. Sequential contribution of L- and P-selectin to leukocyte rolling in vivo. J. Exp. Med. 181:669-675.

44. Ley, K., A. Zakrzewicz, C. Hanski, L.M. Stoolman, and G.S. Kansas. 1995. Sialylated O-glycans and L-selectin sequentially mediate myeloid cell rolling in vivo. Blood. 85:3727-3735.

45. Lorant, D.E., K.D. Patel, T.M. McIntyre, R.P. McEver, S.M. Prescott, and G.A. Zimmerman. 1991. Coexpression of GMP-140 and PAF by endothelium stimulated by histamine or thrombin: a juxtacrine system for adhesion and activation of neutrophils. J. Cell Biol. 115:223-234.

46. Luscinskas, F.W., A.F. Brock, M.A. Arnaout, and M.A. Gimbrone, Jr. 1989. Endothelial-leukocyte adhesion molecule-1 dependent and leukocyte (CD11/CD18)-dependent mechanisms contribute to polymorphonuclear leukocyte adhesion to cytokine-activated human vascular endothelium. J. Immunol. 142:2257-2263.

47. Luscinskas, F.W., M.I. Cybulsky, J.M. Kiely, C.S. Peckins, V.M. Davis, and M.A. Gimbrone, Jr. 1991. Cytokine-activated human endothelial monolayers support enhanced neutrophil transmigration via a mechanism involving both endothelial-leukocyte adhesion molecule-1 (ELAM-1) and intercellular adhesion molecule-1 (ICAM-1). J. Immunol. 146:1617-1625.

48. Luscinskas, F.W., G.S. Kansas, H. Ding, P. Pizcueta, B. Schleiffenbaum, T.F. Tedder, and M.A. Gimbrone, Jr. 1994. Monocyte rolling, arrest and spreading on IL-4-activated vascular endothelium under flow is mediated via sequential action of L-selectin $\beta 1$-integrins, and $\beta 2$-integrins. $J$. Cell Biol. 125:1417-1427.

49. Luscinskas, F.W., H. Ding, P. Tan, D. Cumming, T.F. Tedder, and M.E. Gerritsen. 1996. L- and P-selectins, but not CD49d (VLA 1/24) integrins, mediate monocyte initial attachment to TNF-alpha-activated vascular endothelium under flow in vitro. J. Immunol. 157:326-335.

50. Marlin, S.D., and T.A. Springer. 1987. Purified intercellular adhesion molecule-1 (ICAM-1) is a ligand for lymphocyte function-associated antigen-1 (LFA-1). Cell. 68:805-811.

51. McEver, R.P., and M.N. Martins. 1984. A monoclonal antibody to a membrane glycoprotein binds only to activated platelets. J. Biol. Chem. 259: 9799-9804.

52. McEver, R.P., J.H. Beckstead, K.L. Moore, L. Marshall-Carlson, and D.F. Bainton. 1989. GP-140, a platelet alpha-granule membrane protein, is also synthesized by vascular endothelial cells and is localized in WeibelPalade bodies. J. Clin. Invest. 84:92-99.

53. McEver, R.P., K.L. Moore, and R.D. Cummings. 1995. Leukocyte trafficking mediated by selectin-carbohydrate interactions. J. Biol. Chem. 270: $11025-11028$

54. Moore, K.L., K.D. Patel, R.E. Bruehl, F. Li, D.A. Johnson, H.S. Lichenstein, R.D. Cummings, D.F. Bainton, and R.P. McEver. 1995. P-selectin glycoprotein ligand-1 mediates rolling of human neutrophils on P-selectin. J. Cell Biol. 128:661-671.

55. Needham, L.K., and R.L. Schnaar. 1993. The HNK-1 reactive sulfoglucuronyl glycolipids are ligands for L-selectin and P-selectin but not E-selectin. Proc. Natl. Acad. Sci. USA. 90:1359-1363.

56. Nelson, R.M., O. Cecconi, W.G. Roberts, A. Aruffo, R.J. Linhardt, and M.P. Bevilacqua. 1993. Heparin oligosaccharides bind L- and P-selectin and inhibit acute inflammation. Blood. 82:3253-3258.

57. Norgard-Sumnicht, K.E., N.M. Varki, and A. Varki. 1993. Calcium-dependent heparin-like ligands for L-selectin in nonlymphoid endothelial cells. Science (Wash. DC). 261:480-483.

58. Norgard-Sumnicht, K.E., and A. Varki. 1995. Endothelial heparan sulfate proteoglycans that bind to L-selectin have glucosamine residues with unsubstituted amino groups. J. Biol. Chem. 270:12012-12024

59. O'Brien, K.D., M.D. Allen, T.O. McDonald, A. Chait, J.M. Harlan, D. Fishbein, J. McCarty, M. Ferguson, K. Hudkins, and C.D. Benjamin 1993. Vascular cell adhesion molecule-1 is expressed in human coronary atherosclerotic plaques. Implications for the mode of progression of advanced coronary atherosclerosis. J. Clin. Invest. 92:945-951.

60. Oxley, S., and R. Sackstein. 1994. Detection of an L-selectin ligand on hematopoietic progenitor cell line. Blood. 84:3299-3306.

61. Patel, K.D., K.L. Moore, M.U. Nollert, and R.P. McEver. 1995. Neutrophils use both shared and distinct mechanisms to adhere to selectins under static and flow conditions. J. Clin. Invest. 96:1887-1896.

62. Picker, L.J., R.A. Warnock, A.R. Burns, C.M. Doerschuk, E.L. Berg, and E.C. Butcher. 1991.The neutrophil selectin LECAM-1 presents carbohydrate ligands to the vascular selectins ELAM-1 and GMP-140. Cell. 66: 921-935.

63. Pouyani, T., and B. Seed. 1995. PSGL-1 recognition of P-selectin is controlled by a tyrosine sulfation consensus at the PSGL-1 amino terminus. Cell. 83:333-343.

64. Puri, K.D., E.B. Finger, G. Gaudernack, and T.A. Springer. 1995. Sialomucin CD34 is the major L-selectin ligand in human tonsil high endothelial venules. J. Cell Biol. 131:261-270.

65. Rosen, S.D., and C.R. Bertozzi. 1994. The selectins and their ligands. Curr Opin. Cell. Biol. 6:663-673.

66. Ruoslahti, E., and Y. Yamaguchi. 1991. Proteoglycans as modulators of growth factor activities. Cell. 64:867-869.

67. Sako, D., X.-J. Chang, K. Barone, G. Vachino, H. White, G. Shaw, G. Veldman, K. Bean, T. Ahern, B. Furie, et al. 1993. Expression cloning of a functional glycoprotein ligand for P-selectin. Cell. 75:1179-1186.

68. Sako, D., K.M. Comess, K.M. Barone, R.T. Camphausen, D.A. Cumming, and G.D. Shaw. 1995. A sulfated peptide segment at the amino terminus of PSGL-1 is critical for P-selectin binding. Cell. 83:323-331.

69. Schlessinger, J., I. Lax, and M. Lemmon. 1995. Regulation of growth factor activation by proteoglycans: what is the role of the low affinity receptors? Cell. 83:357-360.

70. Shen, J., F.W. Luscinskas, A. Conolly, C.F. Dewey, and M.A. Gimbrone, Jr. 1992. Fluid shear stress modulates cytosolic free calcium in vascular endothelial cells. Am. J. Physiol. 262:C384-390.

71. Smith, C.W., T.K. Kishimoto, O. Abbass, B. Hughes, R. Rothlein, L.V. McIntire, E. Butcher, and D.C. Anderson. 1991. Chemotactic factors regulate lectin adhesion molecule 1 (LECAM-1)-dependent neutrophil adhesion to cytokine-stimulated endothelial cells in vitro. J. Clin. Invest. 87: 609-618.

72. Spertini, O., G.S. Kansas, K.A. Reimann, C.R. Mackay, and T.F. Tedder. 1991. Function and evolutionary conservation of distinct epitopes on the leukocyte adhesion molecule-1 (TQ-1, Leu-8) that regulate leukocyte migration. J. Immunol. 147:942-949.

73. Spertini, O., F.W. Luscinskas, J.M. Munro, G.S. Kansas, J.D. Griffin, M.A. Gimbrone, and T.F. Tedder. 1991. Leukocyte adhesion molecule-1 (LAM-1, L-selectin) interacts with an inducible endothelial cell ligand to support leukocyte adhesion. J. Immunol. 147:2565-2573.

74. Spertini, O., G.S. Kansas, J.M. Munro, J.D. Griffin, and T.F. Tedder. 1991. Regulation of leukocyte migration by activation of the leukocyte adhesion molecule-1 (LAM-1) selectin. Nature (Lond.). 349:691-693.

75. Spertini, O., B. Schleiffenbaum, C. White-Owen, P. Ruiz, Jr., and T.F. Tedder. 1992. ELISA for quantitation of L-selectin shed from leukocytes in vivo. J. Immunol. Methods. 156:115-123.

76. Spertini, O., F.W. Luscinskas, M.A. Gimbrone Jr., and T.F. Tedder. 1992. Monocyte attachment to activated human vascular endothelium in vitro is mediated by leukocyte adhesion molecule-1 (L-selectin) under nonstatic conditions. J. Exp. Med. 175:1789-1792.

77. Spertini, O., P. Callegari, A.-S. Cordey, J. Hauert, J. Joggi, V. von Fliedner, and M. Schapira. 1994. High levels of the shed form of L-selectin (sL-selectin) are present in patients with acute leukemia and inhibit blast cell adhesion to activated endothelium. Blood. 84:1249-1256.

78. Spertini, O., A.-S. Cordey, N. Monai, L. Giuffrè, and M. Schapira. 1996. P-selectin glycoprotein ligand-1 (PSGL-1) is a ligand for L-selectin on neutrophils, monocytes and $\mathrm{CD} 34^{+}$hematopoietic progenitor cells. $J$. Cell Biol. 135:523-531.

79. Springer, T.A. 1994. Traffic signals for lymphocyte recirculation and leukocyte emigration: the multistep paradigm. Cell. 76:301-314.

80. Tanaka, Y., D.H. Adams, and S. Shaw. 1993. Proteoglycans on endothelial cells present adhesion-inducing cytokines to leukocytes. Immunol. Today. 14:111-114.

81. Tanaka, H., G.K. Sukhova, S.J. Swanson, S.K. Clinton, P. Ganz, M.I. Cybulsky, and P. Libby. 1993. Sustained activation of vascular cells and leukocytes in the rabbit aorta after balloon injury. Circulation. 88:17881803.

82. Tanaka, H., G.K. Sukhova, S.J. Swanson, M.I. Cybulsky, F.J. Schoen, and P. Libby. 1994. Endothelial and smooth muscle cells express leukocyte adhesion molecules heterogeneously during acute rejection of rabbit cardiac allografts. Am. J. Pathol. 144:938-951.

83. Tedder, T.F., T.J. Ernst, G.D. Demetri, C.M. Isaacs, D.A. Adler, and C.M. Disteche. 1989. Isolation and chromosomal localization of cDNAs encoding a novel human lymphocyte cell-surface molecule, LAM1: homology with the mouse lymphocyte homing receptor and other human adhesion proteins. J. Exp. Med. 170:123-133.

84. Tedder, T.F., D.A. Steeber, A. Chen, and P. Engel. 1995. The selectins: vascular adhesion molecules. FASEB J. 9:866-873.

85. Tedder, T.F., D.A. Steeber, and P. Pizcueta. 1995. L-selectin-deficient mice have impaired leukocyte recruitment into inflammatory sites. $J$. Exp. Med. 181:2259-2264.

86. True, D.D., M.S. Singer, L.A. Lasky, and S.D. Rosen. 1990. Requirement for sialic acid on the endothelial ligand of a lymphocyte homing receptor. J. Cell Biol. 111:2757-2764.

87. Tu, L.L., A.J. Chen, M.D. Delahunty, K.L. Moore, S.R. Watson, R.P. McEver, and T.F. Tedder. 1996. L-selectin binds to P-selectin glycoprotein ligand-1 on leukocytes. J. Immunol. 157:3995-4004.

88. Varki, A. 1994. Selectin ligands. Proc. Natl. Acad. Sci. USA. 91:7390-7397.

89. von Andrian, U.H., J.D. Chambers, L.M. McEvoy, R.F. Bargatze, K.-E. Arfors, and E.C. Butcher. 1991. Two step model of leukocyte-endothelial cell interaction in inflammation: distinct roles for LECAM-1 and the leukocyte $\beta 2$ integrins in vivo. Proc. Natl. Acad. Sci. USA. 88:7538-7542.

90. von Andrian, U.H., J.D. Chambers, E.L. Berg, S.A. Michie, D.A. Brown, D. Karolak, L. Ramezani, E.M. Berger, K.-E. Arfors, and E.C. Butcher. 1993. L-selectin mediates neutrophil rolling in inflamed venules through sialyl LewisX-dependent and -independent recognition pathways. Blood. 82:182-191.

91. von Adrian, U.H., S.R. Hasslen, R.D. Nelson, S.L. Erlandsen, and E.C. Butcher. 1995. A central role for microvillous receptor presentation in 
leukocyte ahdesion under flow. Cell. 82:989-999.

92. Watson, S.R., C. Fennie, and L.A. Lasky. 1991. Neutrophil influx into an inflammatory site inhibited by a soluble homing receptor-IgG chimera. Nature (Lond.). 349:164-167.

93. Wilkins, P.P., K.L. Moore, R.P. McEver, and R.D. Cummings. 1995. Ty- rosine sulfation of $\mathrm{P}$-selectin glycoprotein ligand-1 is required for high affinity binding to P-selectin. J. Biol. Chem. 270:22677-22680.

94. Yanagishita, M., and V.C. Hascall. 1992. Cell surface heparan sulfate proteoglycans. J. Biol. Chem. 267:9451-9454. 